\title{
Point defects and oxidation state of additives in rare-earth metal doped crystals of lead telluride PbTe:Ln
}

\author{
Dmytro FREIK ${ }^{1 *}$, Liliya TUROVSKA ${ }^{1}$, Volodymyra BOYCHUK ${ }^{1}$ \\ ${ }^{1}$ Institute of Physics and Chemistry, Precarpathian National Vasyl Stefanyk University, \\ Shevchenka St. 57, 76018 Ivano-Frankivsk, Ukraine \\ * Corresponding author. Tel.: +380-34-2759214; fax: +380-34-2759214; e-mail: freik@pu.if.ua
}

Received January 13, 2011; accepted May 18, 2011; available on-line November 8, 2011

Models describing the point defects in rare-earth metal Ln (Sm, Gd, La, Pr) doped lead telluride crystals have been developed. The parameters of the charge disproportionation of the additives and their impact on the conductivity type in $p$-PbTe:Ln crystals were determined. Based on the proposed crystal-quasi-chemical formulae, the dependencies of the concentration of point defects and free carriers and the Hall concentration of current carriers on the doping agent content were calculated.

Lead telluride / Rare-earth metals / Point defects / Crystal-quasi-chemical formulae

\section{Точкові дефекти і зарядовий стан домішок у легованих рідкісноземельними металами кристалах плюмбум телуриду PbTe:Ln}

\author{
Дмитро ФРЕЇК ${ }^{1 *}$, Лілія ТУРОВСьКА ${ }^{1}$, Володимира БОЙЧУК ${ }^{1}$ \\ ${ }^{1}$ Прикарпатський національний університет імені Василя Стефаника, \\ вул. Шевченка 57, 76018 м. Івано-Франківськ, Україна \\ * Контактна особа. Тел.: +380-34-2759214; факс:+380-34-2759214; e-mail: freik@pu.if.ua
}

Розроблені моделі точкових дефектів у легованих рідкісноземельними металами Ln (Sm, Gd, La, Pr) кристалах плюмбум телуриду. Визначено значення величин диспропорціонування зарядового стану домішок та їх вплив на зміну типу провідності в кристалах $p$-PbTe:Ln. На основі запропонованих кристалоквазіхімічних формул розраховано залежності концентрації точкових дефектів, вільних носіїв, холлівської концентрації носіїв заряду від вмісту легуючої домішки.

Плюмбум телурид / Рідкісноземельні метали / Точкові дефекти / Кристалоквазіхімічні формули

Вступ

Плюмбум телурид - $\quad$ перспективний напівпровідниковий матеріал для пристроїв термоелектричного перетворення енергії, що функціонують в області температур (500-850) К. $\mathrm{PbTe}$ кристалізується у структурі типу $\mathrm{NaCl}$ (просторова група $\mathrm{Fm}-3 \mathrm{~m}-\mathrm{O}_{\mathrm{h}}^{5}$ ) 3 параметром гратки $a=6.452 \AA$ (Рис. 1) i характеризується двосторонньою областю гомогенності, яка визначає $n$ - або $p$-тип провідності і складний спектр власних точкових дефектів [1-4].

Важливими чинниками, які визначають робочі характеристики приладових структур $є$ точкові дефекти базового матеріалу, якими можна суттєво керувати за рахунок легування [1-5].

Рідкісноземельні метали (РЗМ) як домішки в кристалах IV-VI привертають до себе велику увагу [6-22]. Основним чином це зумовлено їх впливом на дефектну підсистему кристалів і можливістю варіювати концентрацію носіїв в широких межах. 
Не зважаючи на достатньо велику кількість робіт, в яких досліджувалися магнітні [6-11], оптичні [12-14], механічні [15] та транспортні властивості легованих рідкісноземельними металами сполук IV-VI $[13,16]$, а також вплив домішки на термоелектричні параметри та концентрацію носіїв базової сполуки [12,17-22], питання, пов'язані із зарядовим станом РЗМ у цих кристалах залишаються відкритими. Відносно причин донорної дії РЗМ немає єдиної думки: одні автори пов'язують іiі 3 безпосереднім впливом трикратно іонізованої домішки, інші - 3 вакансіями в положеннях халькогену.

Метою даної роботи $є$ 3'ясування кристалохімічного механізму дефектоутворення в кристалах плюмбум телуриду, легованих РЗМ, акцентуючи увагу на чотирьох із них: самарію, гадолінію, лантану та празеодиму.

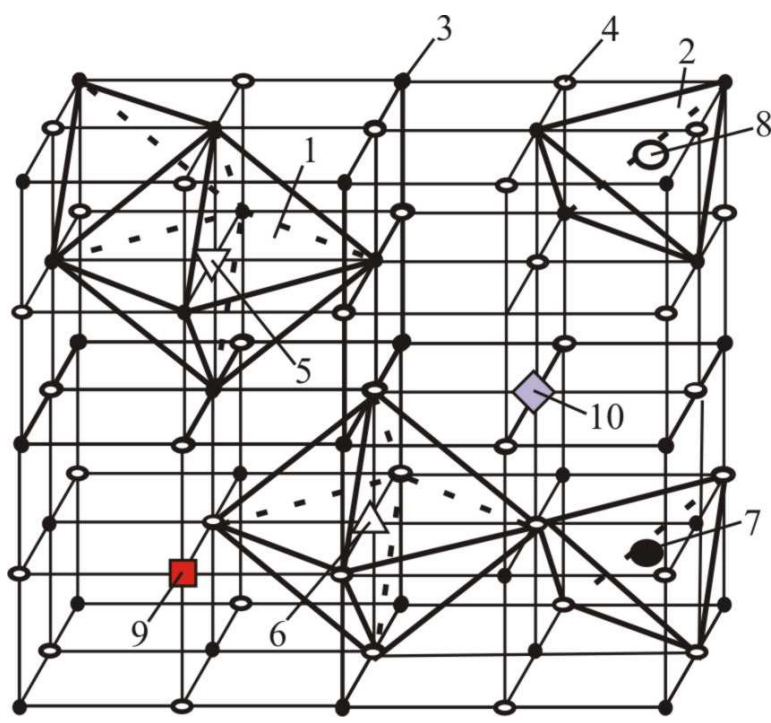

Рис. 1 Кристалічна модель дефектної підсистеми PbTe:Ln: 1 - октаедрична порожнина (ОП), 2- тетраедрична порожнина (ТП), 3 - атом плюмбуму у вузлі кристалічної гратки $\mathrm{Pb}_{\mathrm{Pb}}^{0}, 4$ - атом телуру у вузлі кристалічної гратки $\mathrm{Te}_{\mathrm{Te}}^{0}, 5$ - вакансія телуру в октаедричному оточенні атомів плюмбуму $\mathrm{V}_{\mathrm{Te}}^{2+}, 6$ - вакансія плюмбуму в октаедричному оточенні атомів телуру $\mathrm{V}_{\mathrm{Pb}}^{2-}, \quad \mathrm{V}_{\mathrm{Pb}}^{1-}, 7$ - міжвузловий плюмбум в тетраедричному оточенні атомів телуру $\mathrm{Pb}_{i}^{2+}, 8-$ міжвузловий телур в тетраедричному оточенні атомів плюмбуму $\mathrm{Te}_{i}^{0}, 9-$ нейтральний Ln в положенні плюмбуму $\operatorname{Ln}_{\mathrm{Pb}}^{0}, 10$ - однозарядний $\operatorname{Ln}$ в положенні плюмбуму $\operatorname{Ln}_{\mathrm{Pb}}^{1+}$.

\section{Кристалоквазіхімічні формули легованих кристалів PbTe:Ln}

За кристалохімічними характеристиками монотелуриди рідкісноземельних елементів подібні до РbTe, зокрема кристалізуються у структурі типу $\mathrm{NaCl}$ з близькими за значенням параметрами гратки [23,24]. У зв'язку із цим 3 боку $\mathrm{PbTe}$ існує достатньо широка область гомогенності для легованих Р3М кристалів $\mathrm{PbTe}$, яка сягає до 5 ат. \% для Sm, 2 ат. \% для Gd, 1 ат. \% для La та $\operatorname{Pr}[19]$.

Валентний стан РЗМ у значній мірі визначає особливості в характері поведінки сполук. Електронна конфігурація атомів РЗМ може бути виражена загальною формулою $4 f^{0-14} 5 s^{2} 5 p^{6} 5 d^{0-1} 6 s^{2}$ [25]; валентними $є 5 d^{1} 6 s^{2}$-електрони, тому стійка ступінь окиснення +3. При цьому в монохалькогенідах РЗМ лише два електрони металу вступають в зв'язок з халькогеном [23], а $f$ стани можуть відігравати роль «квазідомішкових» рівнів донорного типу із незначною енергією активації $f$-електронів у зону провідності. Останнє i $\epsilon$ причиною спостережуваного в ході експерименту зростання концентрації носіїв при легуванні (Рис. 2a).

Таким чином, вважаючи, що іон РЗМ може перебувати, крім двозарядного $\mathrm{Ln}^{2+}$, ще й в тризарядному стані $\mathrm{Ln}^{3+}, \quad$ таке диспропорціонування можна представити у вигляді такої схеми:

$$
\begin{aligned}
& \operatorname{Ln}^{2+} \rightarrow \operatorname{Ln}_{z}^{3+}+\operatorname{Ln}_{1-z}^{2+}+z \mathrm{e}^{-}, \\
& \text {де } \quad z=\frac{\operatorname{Ln}^{3+}}{\operatorname{Ln}^{3+}+\operatorname{Ln}^{2+}}-
\end{aligned}
$$

коефіцієнт

диспропорціонування зарядового стану домішки Ln (Sm, Gd, La, Pr).

B основу методу кристалоквазіхімічного аналізу на основі антиструктури покладено суперпозицію кристалоквазіхімічних кластерів базової і легуючої сполук [26]. Антиструктурою плюмбум телуриду є галеніт $\mathrm{V}_{\mathrm{Pb}}^{/ /} \mathrm{V}_{\mathrm{Te}}^{\bullet \bullet}$, де $\mathrm{V}_{\mathrm{Pb}}^{\prime /} \mathrm{i}_{\mathrm{Te}}^{\bullet \bullet}$ - двократно заряджені негативна вакансія плюмбуму і позитивна вакансія телуру, «/» і «•»негативний і позитивний заряди, відповідно.

Слід зазначити, що іон $\mathrm{Ln}^{2+}$ буде нейтральним дефектом по відношенню до катіонної підгратки $\mathrm{Pb}^{2+}$ у $\mathrm{PbTe} \quad\left(\mathrm{Ln}^{2+} \rightarrow \mathrm{Ln}_{\mathrm{Pb}}^{0}\right), \quad$ a iоH $\mathrm{Ln}^{3+}-$ однозарядним домішковим центром $\left(\mathrm{Ln}^{3+} \rightarrow \mathrm{Ln}_{\mathrm{Pb}}^{+}\right)$. Таким чином, легуючий кластер за умови розміщення іонів Ln у катіонній підгратці (Рис. 1) буде мати вигляд:

$\mathrm{V}_{\mathrm{Pb}}^{\prime \prime} \mathrm{V}_{\mathrm{Te}}^{\bullet \bullet}+\mathrm{LnTe} \rightarrow$

$\left[\operatorname{Ln}_{z}^{\bullet} \operatorname{Ln}_{1-z}^{\times}\right]_{\mathrm{Pb}} \mathrm{Te}_{\mathrm{Te}}^{\times}+z \mathrm{e}^{\prime}$

де $\mathrm{e}^{\prime}$ - електрони, «х» - нейтральний заряд.

Кристалоквазіхімічна формула $n$-PbTe зі складним спектром точкових дефектів у катіонній 
підгратці (одно- і двозарядні вакансії плюмбуму $\left.\mathrm{V}_{\mathrm{Pb}}^{\prime}, \mathrm{V}_{\mathrm{Pb}}^{\prime \prime}\right)$, згідно [27], має вигляд:

$\left[\mathrm{Pb}_{1-\alpha \sigma}^{\times} \mathrm{V}_{\alpha \sigma(1-\delta)}^{\prime \prime} \mathrm{V}_{\alpha \sigma \delta \delta}^{\prime}\right]_{\mathrm{Pb}} \times$
$\left[\mathrm{Te}_{1-\alpha}^{\times} \mathrm{V}_{\alpha}^{\bullet \bullet}\right]_{\mathrm{Te}}\left(\mathrm{Pb}_{\alpha \sigma}^{\bullet \bullet}\right)+(2 \alpha+\alpha \sigma \delta) \mathrm{e}^{\prime}$

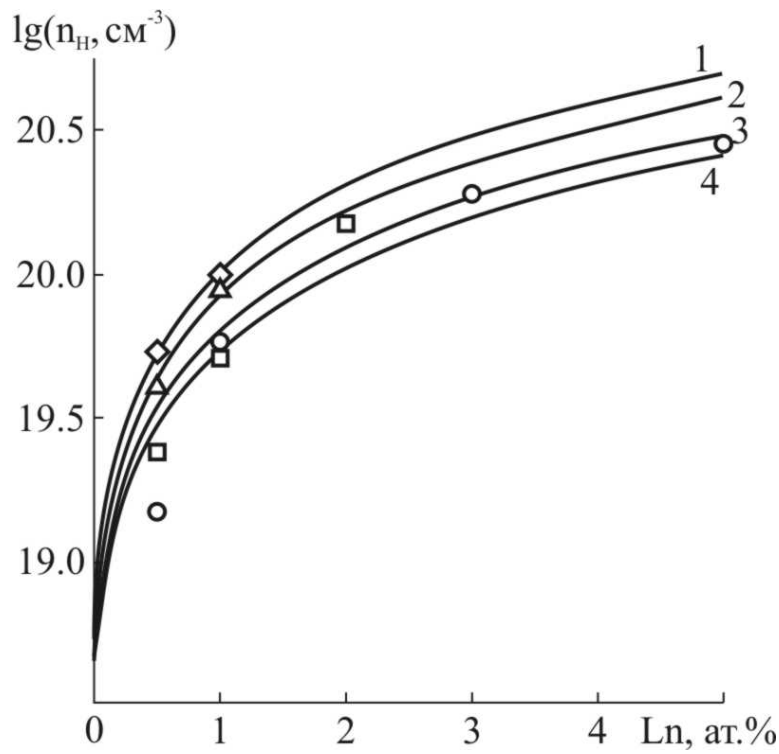

a

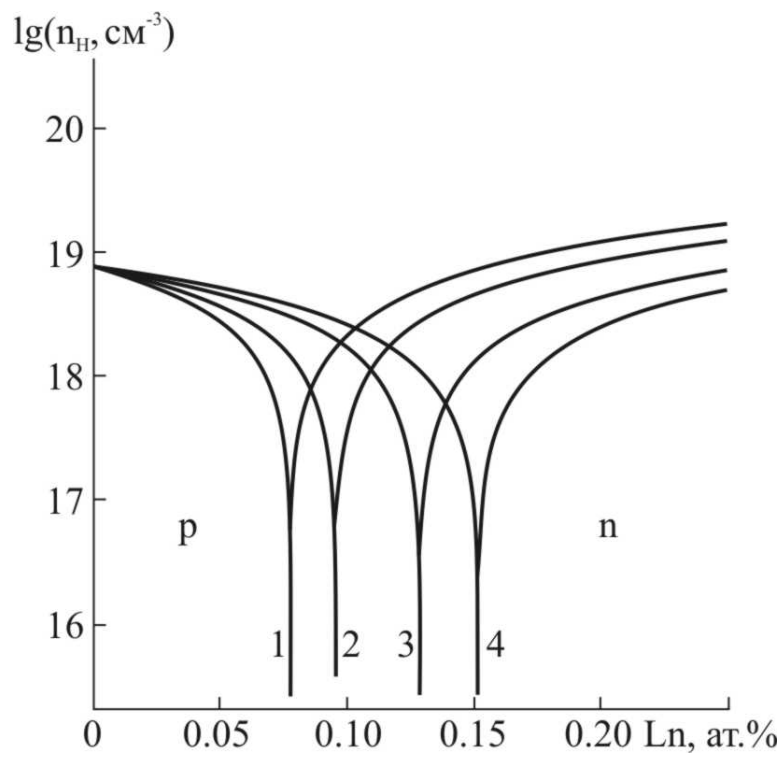

б

Рис. 2 Залежність холлівської концентрації носіїв струму $\left(n_{H}\right)$ в кристалах $n$-PbTe:Ln (a) $(\alpha=0.006$ ат. \%) $\quad$ та $\quad p$-PbTe:Ln (б) $(\beta=0.013$ ат. \%) від вмісту легуючої домішки Ln: $1-\diamond-\operatorname{Pr}, 2-\Delta-\mathrm{La}, 3-\mathrm{O}-$ Sm, $4-\square-$ Gd. Криві - розрахунок, точки експеримент [19].
Кристалоквазіхімічна формула $n$-PbTe:Ln як суперпозиція кристалоквазіхімічної формули n-PbTe (3) $з$ легуючим кластером (2) запишеться як:

$$
\begin{aligned}
& (1-x)\left\{\left[\mathrm{Pb}_{1-\alpha \sigma}^{\times} \mathrm{V}_{\alpha \sigma(1-\delta)}^{\prime \prime} \mathrm{V}_{\alpha \sigma \delta}^{\prime}\right]_{\mathrm{Pb}} \times\right. \\
& \left.\left[\mathrm{Te}_{1-\alpha}^{\times} \mathrm{V}_{\alpha}^{\bullet \bullet}\right]_{\mathrm{Te}}\left(\mathrm{Pb}_{\alpha \sigma}^{\bullet \bullet}\right)_{i}+(2 \alpha+\alpha \sigma \delta) \mathrm{e}^{\prime}\right\}+ \\
& x\left\{\left[\operatorname{Ln}_{z}^{\bullet} \operatorname{Ln}_{1-z}^{\times}\right]_{\mathrm{Pb}} \mathrm{Te}_{\mathrm{Te}}^{\times}+z \mathrm{e}^{\prime}\right\} \rightarrow \\
& {\left[\mathrm{Pb}_{(1-x)(1-\alpha \sigma)}^{\times} \mathrm{Ln}_{z x} \operatorname{Ln}_{(1-z) x}^{\times} \mathrm{V}_{\alpha \sigma(1-\delta)(1-x)}^{\prime \prime} \mathrm{V}_{\alpha \sigma \delta(1-x)}^{\prime}\right]_{\mathrm{Pb}} \times} \\
& {\left[\mathrm{Te}_{(1-\alpha)(1-x)+x}^{\times} \mathrm{V}_{\alpha(1-x)}^{\bullet \bullet}\right]_{\mathrm{Te}}\left(\mathrm{Pb}_{\alpha \sigma(1-x)}^{\bullet \bullet}\right)_{i}+} \\
& {[(2 \alpha+\alpha \sigma \delta)(1-x)+x z] \mathrm{e}^{\prime}}
\end{aligned}
$$

де $x$ - мольна частка LnTe, $\alpha$ - величина початкового відхилення від стехіометрії на боці $\mathrm{Pb}, \delta-\quad$ коефіцієнт диспропорціонування зарядового стану вакансій плюмбуму, $\sigma$ - частка міжвузлових атомів плюмбуму.

Аналогічним чином запишемо кристалоквазіхімічну формулу $p$-PbTe:Ln. Маючи на увазі, що вираз для $p$-PbTe, згідно [27]:

$$
\begin{aligned}
& {\left[\mathrm{Pb}_{1-\beta}^{\times} \mathrm{V}_{\beta(1-\delta)}^{\prime \prime} \mathrm{V}_{\beta \delta}^{\prime}\right]_{\mathrm{Pb}}\left[\mathrm{Te}_{1-\beta \gamma}^{\times} \mathrm{V}_{\beta \gamma}^{\bullet \bullet}\right]_{\mathrm{Te}} \times} \\
& \left(\mathrm{Te}_{\beta \gamma}^{\times}\right)_{i}+\beta(2-2 \gamma-\delta) \mathrm{h}^{\bullet}
\end{aligned}
$$

то для $p$-PbTe:Ln отримаємо:

$$
\begin{aligned}
& (1-x)\left\{\left[\mathrm{Pb}_{1-\beta}^{\times} \mathrm{V}_{\beta(1-\delta)}^{\prime \prime} \mathrm{V}_{\beta \delta}^{\prime}\right]_{\mathrm{Pb}}\left[\mathrm{Te}_{1-\beta \gamma}^{\times} \mathrm{V}_{\beta \gamma}^{\bullet \bullet}\right]_{\mathrm{Te}} \times\right. \\
& \left.\left(\mathrm{Te}_{\beta \gamma}^{\times}\right)_{i}+\beta(2-2 \gamma-\delta) \mathrm{h}^{\bullet}\right\}+ \\
& x\left\{\left[\operatorname{Ln}_{z}^{\bullet} \operatorname{Ln}_{1-z}^{\times}\right]_{\mathrm{Pb}} \mathrm{Te}_{\mathrm{Te}}^{\times}+z \mathrm{e}^{\prime}\right\} \rightarrow \\
& {\left[\mathrm{Pb}_{(1-\beta)(1-x)}^{\times} \operatorname{Ln}_{z x}^{\bullet} \operatorname{Ln}_{(1-z) x}^{\times} \mathrm{V}_{\beta(1-\delta)(1-x)}^{\prime \prime} \mathrm{V}_{\beta \delta(1-x)}^{\prime}\right]_{\mathrm{Pb}} \times} \\
& {\left[\mathrm{Te}_{1-\beta \gamma+\beta \gamma x}^{\times} \mathrm{V}_{\beta \gamma(1-x)}^{\bullet}\right]_{\mathrm{Te}}\left(\mathrm{Te}_{\beta \gamma(1-x)}^{\times}\right)_{i}+} \\
& \beta(2-2 \gamma-\delta)(1-x) \mathrm{h}^{\bullet}+z x \mathrm{e}^{\prime}
\end{aligned}
$$

де $\beta$ - величина початкового відхилення від стехіометрії на боці Те, $\mathrm{h}^{\bullet}$ - дірки.

\section{Розрахунок концентрації дефектів i носіїв струму}

Запропонований механізм легування, а також кристалоквазіхімічні формули (4) та (6) дають можливість знайти аналітичні залежності як концентрації окремих точкових дефектів, так i носіїв струму від величини відхилення від стехіометричного складу у базовій сполуці $(\alpha, \beta)$ i вмісту домішки $(x)$. Так, зокрема для $n$-PbTe:Ln, згідно 3 кристалоквазіхімічною формулою (4), повне рівняння електронейтральності:

$$
\begin{aligned}
& n+\left|q_{\mathrm{V}_{\mathrm{Pb}}^{\prime \prime}}\right|\left[\mathrm{V}_{\mathrm{Pb}}^{\prime \prime}\right]+\left|q_{\mathrm{V}_{\mathrm{Pb}}^{\prime}}\right|\left[\mathrm{V}_{\mathrm{Pb}}^{\prime}\right]= \\
& \left|q_{\mathrm{V}_{\mathrm{Te}}}\right|\left[\mathrm{V}_{\mathrm{Te}}^{\bullet \bullet}\right]+\left|q_{\mathrm{Pb}_{\mathrm{i}}}\right|\left[\mathrm{Pb}_{\mathrm{i}}^{\bullet \bullet}\right]+\left|q_{\mathrm{Ln}_{\mathrm{Pb}}}\right|\left[\mathrm{Ln}_{\mathrm{Pb}}^{\bullet}\right] \\
& \text { де } n=A((2 \alpha+\alpha \gamma \delta)(1-x)+x z), \\
& {\left[\mathrm{V}_{\mathrm{Pb}}^{\prime \prime}\right]=A \alpha \sigma(1-\delta)(1-x),\left[\mathrm{V}_{\mathrm{Pb}}^{\prime}\right]=A \alpha \sigma \delta(1-x),} \\
& {\left[\mathrm{Ln}_{\mathrm{Pb}}^{\bullet}\right]=A z x,\left[\mathrm{~V}_{\mathrm{Te}}^{\bullet \bullet}\right]=A \alpha(1-x),}
\end{aligned}
$$


$\left[\mathrm{Pb}_{i}^{\bullet \bullet}\right]=A \alpha \sigma(1-x),\left|q_{\mathrm{V}_{\mathrm{Pb}}^{\prime}}\right|=\left|q_{\mathrm{Ln}_{\mathrm{Pb}}}\right|=1$,

$\left|q_{\mathrm{V}_{\mathrm{Pb}}^{\prime \prime}}\right|=\left|q_{\mathrm{V}_{\mathrm{Te}}}\right|=\left|q_{\mathrm{Pb}} \cdot\right|=2-$ заряди дефектів.

Тут $A=\frac{2 Z}{a^{3}}, Z-$ число структурних одиниць в елементарній комірці, $a$ - параметр гратки.

Холлівська концентрація носіїв струму $n_{H}$ у $n$ PbTe:Ln буде визначатися як:

$n_{H}=A((2 \alpha+\alpha \gamma \delta)(1-x)+x z)$.

Аналогічно для $p$-PbTe:Ln, згідно (6), рівняння електронейтральності:

$$
\begin{aligned}
& n+\left|q_{\mathrm{V}_{\mathrm{Pb}}^{\prime \prime}}\right|\left[\mathrm{V}_{\mathrm{Pb}}^{\prime \prime}\right]+\left|q_{\mathrm{V}_{\mathrm{Pb}}^{\prime}}\right|\left[\mathrm{V}_{\mathrm{Pb}}^{\prime}\right]= \\
& p+\left|q_{\mathrm{V}_{\mathrm{Te}}^{\bullet .}}\right|\left[\mathrm{V}_{\mathrm{Te}}^{\bullet \bullet}\right]+\left|q_{\mathrm{Ln}_{\mathrm{Pb}}}\right|\left[\mathrm{Ln}_{\mathrm{Pb}}^{\bullet}\right]
\end{aligned},
$$

де $\quad n=A z x, \quad p=A \beta(2-2 \gamma-\delta)(1-x)$,

$\left[\mathrm{V}_{\mathrm{Pb}}^{\prime \prime}\right]=A \beta(1-\delta)(1-x), \quad\left[\mathrm{V}_{\mathrm{Pb}}^{\prime}\right]=A \beta \delta(1-x)$,

$\left[\operatorname{Ln}_{\mathrm{Pb}}^{\bullet}\right]=A z x, \quad\left[\mathrm{~V}_{\mathrm{Te}}^{\bullet \bullet \bullet}\right]=A \beta \gamma(1-x)$,

$\left|q_{\mathrm{V}_{\mathrm{Pb}}^{\prime}}\right|=\left|q_{\mathrm{Ln}_{\mathrm{Pb}}}\right|=1,\left|q_{\mathrm{V}_{\mathrm{Pb}}^{\cdot}}\right|=\left|q_{\mathrm{V}_{\mathrm{Te}}^{\cdot \cdot}}\right|=2$.

Холлівська концентрація в цьому випадку:

$n_{H}=A|\beta(2-2 \gamma-\delta)(1-x)-z x|$.

Результати проведених розрахунків холлівської концентрації та концентрації точкових дефектів наведено на Рис. 2,3.

\section{Результати та обговорення}

Припущення про одночасне існування домішки в двох зарядових станах та проведені на основі цього розрахунки (Рис. 2,3) підтверджують донорну дію домішки РЗМ в кристалах плюмбум телуриду і задовільно пояснюють експериментальні результати. Зокрема, збільшення вмісту легуючої домішки в електронних кристалах $n$-PbTe:Ln за умови реалізації двозарядних $\mathrm{Ln}^{2+}$ $\left(\operatorname{Ln}_{\mathrm{Pb}}^{0}\right)$ і тризарядних $\operatorname{Ln}^{3+}\left(\operatorname{Ln}_{\mathrm{Pb}}^{1+}\right)$ станів іонів Р3М має місце зростання концентрації основних носіїв (Рис. 2a). Порівнюючи розрахунки із експериментом (Рис. 2a), можна визначити значення коефіцієнтів диспропорціонування зарядового стану домішки для всіх розглянутих РЗМ: самарію $z_{\mathrm{Sm}} \approx 0.2$, гадолінію $z_{\mathrm{Gd}} \approx 0.17$, лантану $z_{\mathrm{La}} \approx 0.27$, празеодиму $z_{\mathrm{Pr}} \approx 0.33$. Останне дає можливість розрахувати концентрації іонів обох типів для певного фіксованого вмісту легуючої домішки. При чому їх співвідношення пояснює той факт, що найбільшу концентрацію носіїв спостерігаємо в кристалах $n$-PbTe:Pr (Рис. 2a, крива 1), а найменшу - в $n$-PbTe:Gd (Рис. 2а, крива 4).

У випадку кристалів 3 початковою дірковою провідністю $p$-PbTe:Ln має місце зменшення концентрації основних носіїв, конверсія провідності з $p$ - на $n$-тип та подальше зростання концентрації електронів (Рис. 2б). При переході від домішок 3 більшим значенням коефіцієнта диспропорціонування зарядового стану $\left(z_{\mathrm{Pr}}\right)$ до домішок 3 меншим $\left(z_{\mathrm{Gd}}\right)$ крива термодинамічного $p$-n-переходу зміщується на бік більших концентрацій легуючої домішки Ln (Рис. 2б), що зумовлено донорним впливом однократно іонізованих домішкових центрів $\operatorname{Ln}_{\mathrm{Pb}}^{1+}$ (зарядовий стан $\mathrm{Ln}^{3+}$ ) у відношенні до кристалічної гратки основної матриці.
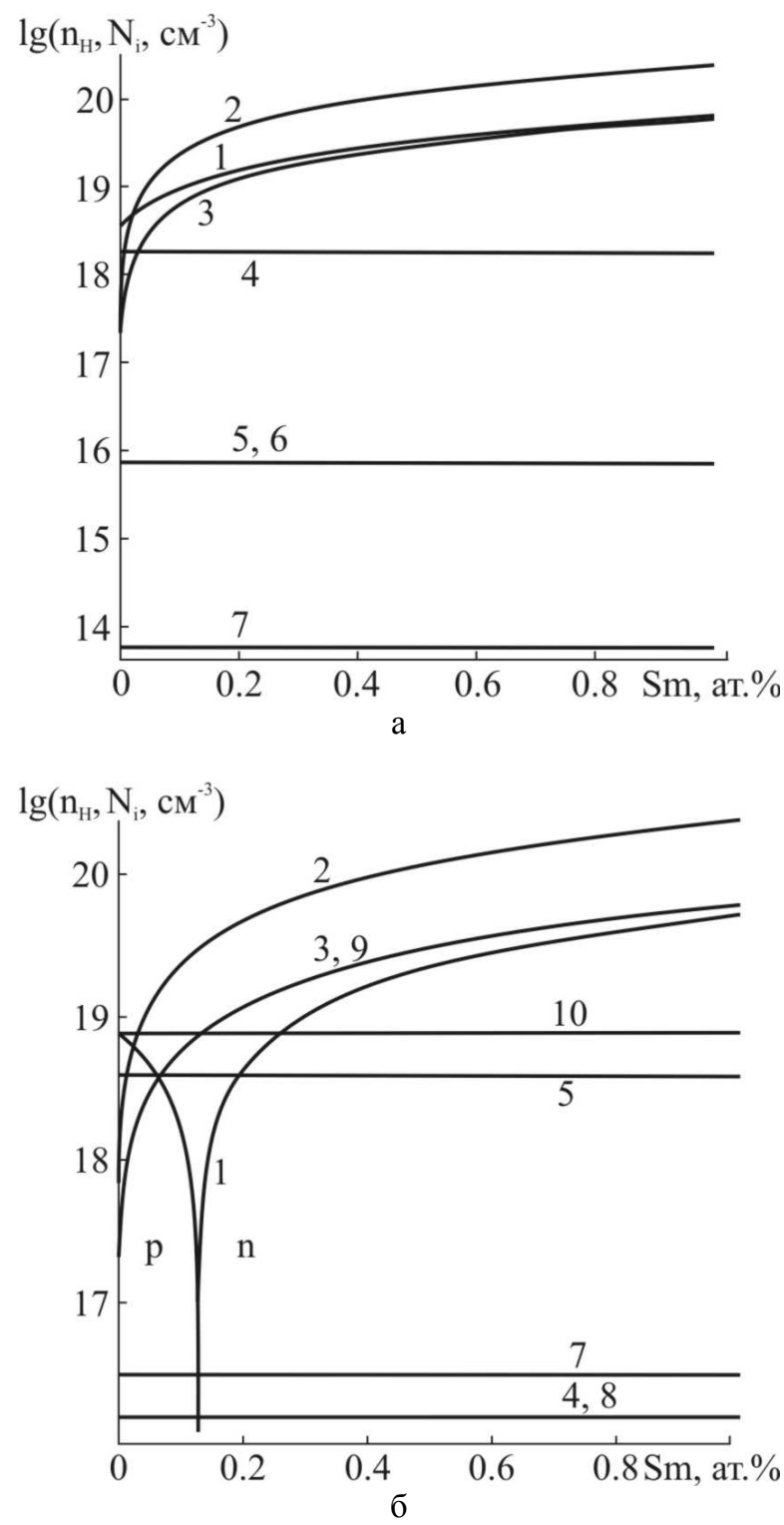

Рис. 3 Залежність холлівської концентрації носіїв струму $\left(1-n_{H}\right)$ та концентрації точкових дефектів у кристалах $n$-PbTe:Sm (a) $(\alpha=0.006$ ат. \%) та $p$-PbTe:Sm (б) $(\beta=0.013$ ат. \%) від вмісту легуючої домішки.

$N_{i}: 2-\mathrm{Sm}_{\mathrm{Pb}}^{0}, 3-\mathrm{Sm}_{\mathrm{Pb}}^{1+}, 4-\mathrm{V}_{\mathrm{Te}}^{2+}, 5-\mathrm{V}_{\mathrm{Pb}}^{2-}$, $6-\mathrm{Pb}_{i}^{2+}, 7-\mathrm{V}_{\mathrm{Pb}}^{1-}, 8-\mathrm{Te}_{\mathrm{i}}^{0}, 9-n, 10-p$. 
На Рис. 3 представлені результати розрахунку концентрації точкових дефектів для випадку легування самарієм. Для кристалів $n$-PbTe:Sm (Рис. 3a) видно, що домінуючими дефектами $\epsilon$ іони самарію, включені у вузлах кристалічної гратки $\mathrm{Sm}_{\mathrm{Pb}}^{0}, \mathrm{Sm}_{\mathrm{Pb}}^{+}$, концентрація яких зростає зі збільшенням вмісту легуючої домішки $\mathrm{Sm}$ (Рис. 3а, криві 2, 3), та вакансії телуру $\mathrm{V}_{\mathrm{Te}}^{2+}$, концентрація яких незначно зменшується (Рис. 3а, крива 4). Співвідношення між домішковими дефектами $\mathrm{Sm}_{\mathrm{Pb}}^{0}$ та $\mathrm{Sm}_{\mathrm{Pb}}^{+}$визначається значенням коефіцієнта диспропорціонування зарядового стану $\left(z_{\mathrm{Sm}}\right)$. Варто відмітити, що концентрація таких власних точкових дефектів як $\mathrm{V}_{\mathrm{Pb}}^{2-}, \mathrm{Pb}^{2+}$, $\mathrm{V}_{\mathrm{Pb}}^{-}$порівняно незначна $\mathrm{i}$ зі зростанням вмісту самарію зменшуються незначно (Рис. 3а, криві 5, $6,7)$. У випадку кристалів $p$-PbTe:Sm (Рис. 3б) домінуючими є домішкові дефекти $\mathrm{Sm}_{\mathrm{Pb}}^{0}, \mathrm{Sm}_{\mathrm{Pb}}^{+}$ (Рис. 36, криві 2, 3), концентрація яких різко зростає 3 ростом концентрації домішки, що $\mathrm{i}$ зумовлює зменшення концентрації дірок (Рис. 3б, крива 10), зростання концентрації електронів (Рис. 36, крива 9) i як результат термодинамічний $p$-n-перехід (Рис. 3б, крива 1 ). Значний вклад в провідність дають двозарядні вакансії плюмбуму $\mathrm{V}_{\mathrm{Pb}}^{2-}$, концентрація яких зменшується незначно (Рис. 36, крива 5). Концентрація $\mathrm{V}_{\mathrm{Te}}^{2+}, \mathrm{V}_{\mathrm{Pb}}^{-}, \mathrm{Te}^{0}$ мала і зі зростанням вмісту самарію практично не змінюється (Рис. 3б, криві 4, 7, 8). Такі закономірності мають місце і для кристалів плюмбум телуриду, легованих лантаном, празеодимом і гадолінієм.

\section{Висновки}

1. Вперше запропоновано кристалоквазіхімічні формули нестехіометричних кристалів $n$ - та $p$ PbTe:Ln (Ln - Sm, Gd, La, Pr), які враховують складний спектр точкових дефектів у плюмбум телуриді $\left(\mathrm{V}_{\mathrm{Pb}}^{2-}, \mathrm{V}_{\mathrm{Pb}}^{1-}, \mathrm{V}_{\mathrm{Te}}^{2+}, \mathrm{Pb}^{2+}, \mathrm{Te}^{0}\right)$ та різний зарядовий стан іонів $\mathrm{P} 3 \mathrm{M} \mathrm{Ln}^{2+}, \mathrm{Ln}^{3+}$.

2. Розраховано залежності холлівської концентрації носіїв струму та точкових дефектів кристалів $n$ - та $p$-PbTe:Ln від складу. Показано, що домінуючими дефектами $\epsilon$ іони Ln у вузлах кристалічної гратки плюмбум телуриду $\operatorname{Ln}_{\mathrm{Pb}}^{0}$, $\mathrm{Ln}_{\mathrm{Pb}}^{+}$, а також двозарядні вакансії телуру $\mathrm{V}_{\mathrm{Te}}^{2+}$ для $n$-PbTe:Ln чи двозарядні вакансії плюмбуму $\mathrm{V}_{\mathrm{Pb}}^{2-}$ для $p$-PbTe:Ln.

3. Визначено значення величин диспропорціонування зарядового стану домішок Р3М, які становлять $0.2,0.17,0.27$, і 0.33 для $\mathrm{Sm}$, $\mathrm{Gd}$, La i Pr, відповідно, та їх вплив на реалізацію термодинамічних $p$ - $n$-переходів для кристалів p-PbTe:Ln.

Робота виконується в рамках наукових проектів Держкомінформнауки Украӥни (державний реєстраційний номер: 0110U007675) та МOH Украӥни (державні реєстраційні номери: 0107U006768 ma 0109U007537).

\section{Літературні посилання}

[1] M.P. Dariel, Z. Dashevsky, A. Jarashnely, S. Shusterman, A. Horowitz, J. Cryst. Growth 234 (2002) 164-170.

[2] Y. Gelbstein, G. Gotesman, Y. Lishzinker, Z. Dashevsky, M.P. Dariel, Scr. Mater. 58 (2008) 251-254.

[3] Н.Х. Абрикосов, Л.М. Шалимова, Полупроводниковые материаль на основе соединений $A^{I V} B^{V I}$, Наука, Москва, 1975, 196 с.

[4] W. Gierlotka, J. Lapsa, D. JendrzejczykHandzlik, J. Alloys Compd. 479 (2009) 152-156.

[5] Д.М. Заячук, В.А. Шендеровський, Укр. фіз. ж. 36 (1991) 1692-1713.

[6] D.M. Zayachuk, J. Magn. Magn. Mater. 322 (2010) 60-64.

[7] A. Errebbahi, F. Terki, S. Charar, C. Fau, S. Isber, M. Tabbal, T.C. Christidis, D. Ravot, J.C. Tedenac, Z. Golacki, J. Magn. Magn. Mater. 248 (2002) 68-74.

[8] D.M. Zayachuk, V.I. Kempnyk, W. Bednarski, S. Waplak, J. Magn. Magn. Mater. 191 (1999) 207-210.

[9] D.M. Zayachuk, V.I. Mikityuk, V.M. Frasunyak, V.V. Shlemkevych, J. Cryst. Growth 311 (2009) 4670-4674.

[10] M. Górska, J.R. Anderson, G. Kido, Z. Golacki, Solid State Commun. 75 (1990) 363-367.

[11] E.P. Skipetrov, N.A. Chernova, L.A. Skipetrova, E.I. Slyn'ko, Mater. Sci. Eng. B 91-92 (2002) 412-415.

[12] P.M. Nikolić, K.M. Paraskevopoulos, M.V. Nikolić, S.S. Vujatović, T.T. Zorba, X. Chatzistavrou, B. Stamenović, D. Luković Golić, V. Blagojević, A. Bojičić, Mater. Chem. Phys. 114 (2009) 185-187.

[13] K. Ozga, K. Nouneh, A. Slezak, I.V. Kityk, J. Alloys Compd. 448 (2008) 49-52.

[14] P.M. Nikolić, W. König, S.S. Vujatović, V. Blagojević, D. Luković, S. Savić, K. Radulović, D. Urošević, M.V. Nikolić, J. Alloys Compd. 433 (2007) 292-295.

[15] Z.K. Zlatanov, Mater. Chem. Phys. 103 (2007) 470-474.

[16] T. Story, M. Górska, M. Arciszewska, E. Grodzicka, Z. Goacki, R.R. Gazka, J. Magn. Magn. Mater. 140-144 (1995) 2041-2042.

[17] D.M. Zayachuk, E.L. Matulenis, V.I. Mikityuk, J. Cryst. Growth 121 (1992) 235-239. 
D. Freik et al., Point defects and oxidation state of additives in rare-earth metal doped crystals...

[18] M.M. Ibrahim, S.A. Saleh, E.M.M. Ibrahim, A.M. Abdel Hakeem, J. Alloys Compd. 452 (2008) 200-204.

[19] G.T. Alekseeva, E.A. Gurieva, M.V. Vedernikov, L.V. Prokof'eva, Yu.I. Ravich, Semiconductors 32 (1998) 716-719.

[20] Д.М. Заячук, О.А. Добрянский, Физ. техн. полупроводн. 32 (1998) 1331-1333.

[21] Д.М. Заячук， В.І. Микитюк， Є.О. Полигач, В.С. Слинько, О.Г. Хандожко, В.В. Шлемкевич, Фіз. хім. тверд. тіла 10 (2009) 272-278.

[22] K. Nouneh, I.V. Kityk, R. Viennois, S. Benet, S. Charar, K.J. Plucinski, J. Alloys Compd. 437 (2007) 39-46.
[23] А.В. Голубков, Е.В. Гончарова, В.П. Жузе, Г.М. Логинов, В.М. Сергеева, И.А. Смирнов, Физические свойства халькогенидов редкоземельных элементов, Наука, Ленинград, 1973, 304 с.

[24] Н.П. Лякишев, Диаграммы состояния двойных металлических систем: Справочник, Т. 3, Кн. 2, Машиностроение, Москва, 2000, $448 \mathrm{c}$

[25] Н.С. Ахметов, Общая и неорганическая химия, Высшая школа, Москва, 2001, 743 с.

[26] С.С. Лисняк, Неорган. матер. 32 (1992) 1913-1917.

[27] В.М. Бойчук, О.В. Ткачик, Л.В. Туровська, Н.І. Дикун, Фіз. хім. тверд. тіла 8 (2007) 366-373. 